\title{
Standards for permanent tooth emergence in Sri Lankan children
}

\author{
Nishanthi Vithanaarachchi ${ }^{1}$, Lakshika Nawarathna ${ }^{2}$, Luxhmen Wijeyeweera ${ }^{1}$ \\ (Index words: permanent teeth, eruption, children, emergence, Sri Lanka)
}

\begin{abstract}
Introduction Determination of population specific standards on the timing and sequence of emergence of the permanent teeth is an essential requirement in pediatric dentistry.
\end{abstract}

Objectives To establish the pattern and emergence time of permanent teeth in children in Sri Lanka.

Methods The cross sectional study was conducted with 3321 school children in the country. Children were randomly selected from each school from age 5-20 years including both genders. Oral cavity was examined using a mouth mirror and probe with natural illumination and erupting stage of each permanent tooth were recorded. All permanent teeth except the third molars were included in the assessment.

Results Females showed earlier eruption of teeth except for central incisors with statistical significance. All the mandibular teeth erupt earlier than their maxillary counterparts except for the premolars. Males showed early emergence of central incisors in left side of the mandible before eruption of first permanent molar. Males showed early eruption of $1^{\text {st }}$ premolar before the eruption of canine in the mandible. The current study identified slightly late eruption of all the permanent teeth than in reported previous study in Sri Lanka.

Conclusion The results of the present study provide reliable references for the emergence of permanent teeth of children in Sri Lanka. Generally median emergence times were delayed compared with the previous study conducted in Sri Lanka.

Ceylon Medical Journal 2021; 66: 44-49

DOI: http://doi.org/10.4038/cmj.v66i1.9348

\section{Introduction}

It is essential to have adequate knowledge of timing and pattern of emergence of permanent teeth for diagnosis and treatment planning in pediatric dentistry and orthodontics. Furthermore, accurate information on tooth emergence is used to supplement with other maturity indications in the diagnosis of certain growth disturbances and in age estimation process in unknown birth records and in identification of human remains in accidents, crimes and natural disasters in forensic dentistry [1].

Mostly the information on the age of permanent teeth emergence used in clinical and academic requirements in Sri Lanka is mainly based on American and European standards. Several factors have been identified by the studies done in the past in relation to determine the timing of tooth emergence of permanent teeth such as gender, ethnicity, environment, socioeconomic and other secular factors $[2,3]$. Therefore, most of the research data has been based on using tooth emergence timing derived from the specific populations [4,5]. Furthermore, some studies have highlighted that nutritional factors, caries status, weight, height and infant health are also needed to be considered as important variables when determining the timing of tooth eruption [6,7].

When considering the cross sectional studies conducted in Sri Lanka regarding tooth emergence, the only study was conducted more than two and half decades ago limiting to the Kandy district [8]. Therefore, it is important to conduct a cross sectional study using a sample representing the population of the country to establish norms for tooth eruption for Sri Lankan children. This study was conducted with a larger sample representing most of the parts of the country aiming to establish pattern and emergence times of permanent teeth in children.

\section{Material and methods}

A cross sectional study was conducted with 3321 children in six provinces of the county including Western, North Central, Sabaragamuwa, Southern, North Western and Uva provinces. Two schools were randomly selected from each province and school children from age of 5 to 18 years were randomly selected from different age groups including both genders. Ethical clearance for the study was obtained from the Ethics Review Committee, Faculty of Dental Science, University of Peradeniya, Sri Lanka.

${ }^{1}$ Department of Community Dental Health, Faculty of Dental Sciences, University of Peradeniya, Sri Lanka, ${ }^{2}$ Department of Statistics and Computer Sciences, Faculty of Science, University of Peradeniya, Sri Lanka.

Correspondence: NV, e-mail: <nvithanaarachchi3@gmail.com>. Received 10 February 2021 and revised version 22 February 2021 accepted 20 March 2021.

This is an open-access article distributed under the terms of the Creative Commons Attribution License, which permits unrestricted use, distribution, and reproduction in any medium, provided the original author and source are credited. 
The observational study (with an intra oral examination only) was conducted with the permission of the management of the schools and with the consent of the parents of the school children. The subjects who were apparently healthy both physically and mentally were included in the study. Children with a history of chronic infectious diseases, nutritional disorders, endocrine disorders, syndromes and developmental disturbances including cleft lip and palate were excluded from the study.

The sample size was calculated according to percentage of population used in the study done by Khan N, 2011 [9]. A minimum study sample size of 3315 was calculated to be necessary; however, we were able to recruit a sample of 3321 children from the schools six provinces of Sri Lanka.

Oral cavity was examined using a mouth mirror and probe with adequate natural illumination (Type III examination) and eruption stage of each specific permanent tooth were recorded by the trained investigators at the school premises. In the present study, the status of tooth eruption was categorized into "not emerged" verses "emerged" (at least one cusp or incisal edge visible). All permanent teeth, except the third molars were included in the assessment of the study. The date of birth of a child was obtained from the school records for the purpose of age estimation. At the same time the children who needed preventive and operative dental procedures were referred to relevant dental clinics during the study period.

The data were analyzed using the statistical software $R$. Anderson darling test was used to check the normality of all the variables. As some of the variables are nonnormal ( $p$-value $<0.05$ ), non-parametric Wilcoxon Rank Sum test was used to determine whether the medians of the males and females groups differ, and to compare the mean time of eruption of maxillary and mandibular teeth. Significant difference was determined at the $95 \%$ confidence level.

\section{Results}

The chronological ages of the eruption of specific permanent teeth were calculated to the nearest month from the date of birth to the date of examination. The mean age of the sample was 10.14 years and 9.86 and 10.39 years were the mean ages of females and males of the sample respectively.

When considering the mean emergence eruption times of both sexes, females showed earlier eruption of teeth compares to males except central incisors which erupt in both males and females around the age of 7.3 years (Table 1 and Figure 1). The difference in the mean eruption of corresponding teeth between males and females for all the teeth except central incisors and $2^{\text {nd }}$ premolars were highly significant $(\mathrm{p}<0.01)$.

When considering the median emergence times, there was a significant difference in contralateral teeth except for PM2. Both left and right sides showed more similar eruption times in both maxillary and mandibular arches.

When investigating the eruption times of permanent teeth of maxillary and mandibular arches, it was revealed that all the mandibular teeth erupt earlier than their maxillary counterparts except in the premolars. The current study showed that both premolars erupt earlier in maxillary arch when compared with the mandibular counterparts in both genders. The eruption difference of both premolars in maxilla and mandible showed statistical significance $(p<0.05)$ except for the right second premolar (Table 2).

Table 1. Mean and median emergence eruption time differences between males and females

\begin{tabular}{|c|c|c|c|c|c|}
\hline \multirow[t]{2}{*}{ Tooth } & \multicolumn{2}{|c|}{ Female } & \multicolumn{2}{|c|}{ Male } & \multirow{2}{*}{$\begin{array}{c}\text { Wilcoxon Rank } \\
\text { Sum Test } \\
\text { p-value }\end{array}$} \\
\hline & Mean (years) & Median (years) & Mean (years) & Median (years) & \\
\hline CI (Central incisor) & 7.072 & 7.010 & 7.283 & 7.250 & $<0.001$ \\
\hline LI (Lateral Incisor) & 8.018 & 7.917 & 8.563 & 8.250 & $<0.001$ \\
\hline C (Canine) & 10.438 & 10.500 & 11.045 & 11.167 & $<0.001$ \\
\hline PM1 (1 $1^{\text {st }}$ premolar $)$ & 10.542 & 10.750 & 10.832 & 10.917 & $<0.001$ \\
\hline PM2 ( $2^{\text {nd }}$ premolar) & 11.108 & 11.496 & 11.320 & 11.500 & $<0.001$ \\
\hline M1 (1 $1^{\text {st }}$ molar $)$ & 6.528 & 6.417 & 6.599 & 6.583 & $<0.001$ \\
\hline M2 (2 ${ }^{\text {nd }}$ molar $)$ & 11.409 & 11.750 & 11.625 & 11.917 & $<0.001$ \\
\hline
\end{tabular}




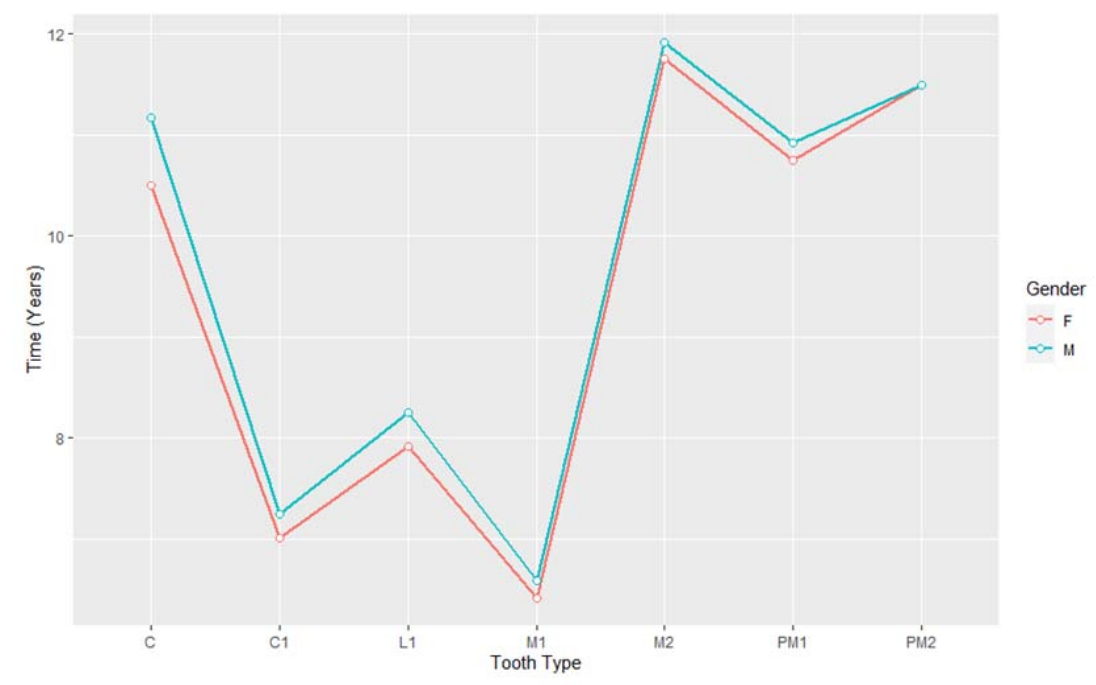

Figure 1. Emergence curves using the median for different teeth in males and females.

Table 2. Mean eruption times of permanent teeth in maxilla and mandible with their measures of speared; Standard deviation, Q1, Median, Q3 and Inter Quartile Range (IQR)

\begin{tabular}{|c|c|c|c|c|c|c|c|c|c|c|c|c|c|}
\hline \multirow[t]{2}{*}{ Side } & \multirow{2}{*}{$\begin{array}{l}\text { Tooth } \\
\text { type }\end{array}$} & \multicolumn{6}{|c|}{ Mandible teeth } & \multicolumn{6}{|c|}{ Maxillary teeth } \\
\hline & & Mean & $S D$ & Q1 & Median & Q3 & $I Q R$ & Mean & $S D$ & Q1 & Median & Q3 & $I Q R$ \\
\hline \multirow[t]{7}{*}{ Left } & $\mathrm{C}$ & 10.64 & 1.32 & 9.75 & 10.75 & 11.67 & 1.92 & 11.00 & 1.32 & 10.08 & 11.08 & 12.00 & 1.92 \\
\hline & I1 & 6.90 & 0.78 & 6.33 & 6.83 & 7.33 & 1.00 & 7.49 & 0.86 & 6.92 & 7.42 & 7.92 & 1.00 \\
\hline & I2 & 8.00 & 1.12 & 7.25 & 7.83 & 8.42 & 1.17 & 8.70 & 1.27 & 7.83 & 8.33 & 9.42 & 1.58 \\
\hline & M1 & 6.50 & 0.65 & 6.08 & 6.42 & 6.83 & 0.75 & 6.63 & 0.77 & 6.08 & 6.58 & 6.96 & 0.88 \\
\hline & M2 & 11.50 & 1.18 & 10.83 & 11.75 & 12.33 & 1.50 & 11.62 & 1.20 & 10.92 & 11.92 & 12.50 & 1.58 \\
\hline & PM1 & 10.84 & 1.19 & 10.00 & 10.92 & 11.75 & 1.75 & 10.68 & 1.27 & 9.83 & 10.80 & 11.67 & 1.83 \\
\hline & PM2 & 11.29 & 1.27 & 10.67 & 11.42 & 12.25 & 1.58 & 11.24 & 1.26 & 10.58 & 11.33 & 12.17 & 1.58 \\
\hline \multirow[t]{7}{*}{ Right } & $\mathrm{C}$ & 10.62 & 1.33 & 9.75 & 10.67 & 11.67 & 1.92 & 11.04 & 1.33 & 10.17 & 11.17 & 12.00 & 1.83 \\
\hline & I1 & 6.91 & 0.80 & 6.33 & 6.83 & 7.33 & 1.00 & 7.50 & 0.87 & 6.92 & 7.42 & 7.92 & 1.00 \\
\hline & I2 & 7.99 & 1.14 & 7.25 & 7.83 & 8.33 & 1.08 & 8.72 & 1.26 & 7.83 & 8.42 & 9.42 & 1.58 \\
\hline & M1 & 6.53 & 0.73 & 6.08 & 6.42 & 6.83 & 0.75 & 6.63 & 0.76 & 6.13 & 6.58 & 7.00 & 0.88 \\
\hline & M2 & 11.48 & 1.16 & 10.83 & 11.75 & 12.33 & 1.50 & 11.65 & 1.25 & 11.00 & 11.92 & 12.50 & 1.50 \\
\hline & PM1 & 10.82 & 1.24 & 10.00 & 10.92 & 11.75 & 1.75 & 10.63 & 1.34 & 9.83 & 10.75 & 11.58 & 1.75 \\
\hline & РM2 & 11.27 & 1.22 & 10.58 & 11.42 & 12.17 & 1.58 & 11.23 & 1.24 & 10.58 & 11.33 & 12.17 & 1.58 \\
\hline \multirow[t]{7}{*}{ Left } & $\mathrm{C}$ & 10.64 & 1.32 & 9.75 & 10.75 & 11.67 & 1.92 & 11.00 & 1.32 & 10.08 & 11.08 & 12.00 & 1.92 \\
\hline & I1 & 6.90 & 0.78 & 6.33 & 6.83 & 7.33 & 1.00 & 7.49 & 0.86 & 6.92 & 7.42 & 7.92 & 1.00 \\
\hline & I2 & 8.00 & 1.12 & 7.25 & 7.83 & 8.42 & 1.17 & 8.70 & 1.27 & 7.83 & 8.33 & 9.42 & 1.58 \\
\hline & M1 & 6.50 & 0.65 & 6.08 & 6.42 & 6.83 & 0.75 & 6.63 & 0.77 & 6.08 & 6.58 & 6.96 & 0.88 \\
\hline & M2 & 11.50 & 1.18 & 10.83 & 11.75 & 12.33 & 1.50 & 11.62 & 1.20 & 10.92 & 11.92 & 12.50 & 1.58 \\
\hline & PM1 & 10.84 & 1.19 & 10.00 & 10.92 & 11.75 & 1.75 & 10.68 & 1.27 & 9.83 & 10.80 & 11.67 & 1.83 \\
\hline & PM2 & 11.29 & 1.27 & 10.67 & 11.42 & 12.25 & 1.58 & 11.24 & 1.26 & 10.58 & 11.33 & 12.17 & 1.58 \\
\hline \multirow[t]{7}{*}{ Right } & $\mathrm{C}$ & 10.62 & 1.33 & 9.75 & 10.67 & 11.67 & 1.92 & 11.04 & 1.33 & 10.17 & 11.17 & 12.00 & 1.83 \\
\hline & I1 & 6.91 & 0.80 & 6.33 & 6.83 & 7.33 & 1.00 & 7.50 & 0.87 & 6.92 & 7.42 & 7.92 & 1.00 \\
\hline & I2 & 7.99 & 1.14 & 7.25 & 7.83 & 8.33 & 1.08 & 8.72 & 1.26 & 7.83 & 8.42 & 9.42 & 1.58 \\
\hline & M1 & 6.53 & 0.73 & 6.08 & 6.42 & 6.83 & 0.75 & 6.63 & 0.76 & 6.13 & 6.58 & 7.00 & 0.88 \\
\hline & M2 & 11.48 & 1.16 & 10.83 & 11.75 & 12.33 & 1.50 & 11.65 & 1.25 & 11.00 & 11.92 & 12.50 & 1.50 \\
\hline & PM1 & 10.82 & 1.24 & 10.00 & 10.92 & 11.75 & 1.75 & 10.63 & 1.34 & 9.83 & 10.75 & 11.58 & 1.75 \\
\hline & PM2 & 11.27 & 1.22 & 10.58 & 11.42 & 12.17 & 1.58 & 11.23 & 1.24 & 10.58 & 11.33 & 12.17 & 1.58 \\
\hline
\end{tabular}


Table 3. Comparison of differences between the maxilla and mandible groups using the Wilcoxon Rank Sum Test

\begin{tabular}{llll}
\hline Tooth type & \multicolumn{2}{c}{ Median } & p-value \\
\cline { 2 - 3 } Left side & Mandible teeth & Maxillary teeth & $<0.001$ \\
C & 10.75 & 11.08 & $<0.001$ \\
I1 & 6.83 & 7.42 & $<0.001$ \\
I2 & 7.83 & 8.33 & $<0.001$ \\
M1 & 6.42 & 6.58 & 0.002 \\
M2 & 11.75 & 11.92 & 0.009 \\
PM1 & 10.92 & 10.80 & 0.225 \\
PM2 & 11.42 & 11.33 & $<0.001$ \\
Right side & & & $<0.001$ \\
C & & & $<0.001$ \\
I1 & 10.67 & 11.17 & 0.001 \\
I2 & 6.83 & 7.42 & $<0.001$ \\
M1 & 7.83 & 8.42 & 0.001 \\
M2 & 6.42 & 6.58 & 0.497 \\
PM1 & 11.75 & 11.92 & 10.75 \\
PM2 & 10.92 & 11.33 & \\
\hline
\end{tabular}

With the analysis of general eruptive sequence of permanent teeth, first permanent molar erupt before the central incisor and followed by the lateral incisors. First premolar erupts before the canine tooth and followed by the eruption of second premolar and second permanent molar teeth. However, such general eruption sequence was slightly deviated with the variation of gender and the type of the jaw. Males showed early emergence of central incisors in left side of the mandible before the eruption of first permanent molar. Further, males showed early eruption of canines in mandible prior to eruption of the first premolar.

\section{Discussion}

Most of the studies related to the tooth emergence are cross sectional studies and few longitudinal studies exit in literature [10]. As stated by Dalberg and MeneazBock, cross sectional studies benefits in collecting larger samples with more population representative results with less risk of bias than longitudinal studies [11].

In the assessment of influence of gender on tooth eruption, girls tended to be advanced compared to the boys except for the central incisors with the current study. Most of the studies showed that permanent teeth erupt earlier in females than males for all the teeth [12]. In contrast to this common finding, some other studies have showed, that eruption pattern remained unchanged between males and females [13].

Results of the current study showed more or less equal eruption patterns in contra lateral teeth in both maxillary and mandibular arches. This finding is compatible with almost all the studies done previously regarding tooth eruption [5].

As highlighted in previous studies, mandibular teeth tend to emerge before their, maxillary counterparts [14,15]. Almost similar results were observed with the current study except for the premolar teeth. Much similar findings were confirmed with some other studies in relation to the early emergence of premolars in maxilla compared to mandible $[5,16,17]$. Therefore, it is paramount importance to consider the early eruption of maxillary premolars in planning the treatment for the children in orthodontics and paedodontics.

Many studies have focused concern about the eruption sequence of permanent teeth and most of the study results have confirmed the following eruption sequence for males and females [8] (Figure2).

Similar to the above findings, current study also showed a similar eruption sequence in males for permanent teeth (except $3^{\text {rd }}$ molar) in maxilla and mandible except for 


\begin{tabular}{lcccccccccccccc}
\multicolumn{10}{c}{ Maxilla } & \multicolumn{11}{c}{ Mandible } \\
& $\mathrm{CI}$ & $\mathrm{Ll}$ & $\mathrm{C}$ & $\mathrm{PM}_{1}$ & $\mathrm{PM}_{2}$ & $\mathrm{M}_{1}$ & $\mathrm{M}_{2}$ & $\mathrm{CI}$ & $\mathrm{Ll}$ & $\mathrm{C}$ & $\mathrm{PM}_{1}$ & $\mathrm{PM}_{2}$ & $\mathrm{M}_{1}$ & $\mathrm{M}_{2}$ \\
Male & 2 & 3 & 6 & 4 & 5 & 1 & 7 & 2 & 3 & 5 & 4 & 6 & 1 & 7 \\
Female & 2 & 3 & 5 & 4 & 6 & 1 & 7 & 2 & 3 & 4 & 5 & 6 & 1 & 7
\end{tabular}

Figure 2. Common eruption sequence of permanent teeth in each jaw in males and females.

the lower central incisor and lower first molar tooth in left side. In the lower arch left central incisor erupts before the eruption of first permanent molar tooth. With regards to the females of the sample, they have followed above common eruption sequence in relation to the mandibular teeth. However, above common eruption sequence was observed in maxillary teeth in females except for the canine and second premolar. In that, upper second premolar erupts before the eruption of canine in this given cohort. These different eruption sequences in maxillary and mandibular arches indifferent genders should be given due consideration in diagnosis and treatment planning of oral health issues in children in Sri Lankan population.

The current study shows slightly late eruption of all the permanent teeth than reported in the past [8]. This could be explained with the results of the national oral health surveys conducted in Sri Lanka which showed reduced dmft levels highlighting less caries frequency and minimal early loss of deciduous teeth as a result of good oral health practices among children in the present decade. Such better maintenance of oral health of children may benefit in long survival of deciduous teeth and timely eruption of permanent teeth in Sri Lankan children [18].

Furthermore, such difference also could be due to contribution from climate, nutrition and socioeconomic factors changed during last two decades in the country and previous researches also have confirmed the relationship of these factors with the changes of emergence pattern of teeth [18].

Table 4 depicts a comparison of mean eruption ages of Sri Lankan girls with other nationalities with various studies conducted in the other populations. Uganda population shows earlier emergence of teeth than other European and Asian countries [19,20,21]. In such comparison, Nepal shows later emergence of permanent teeth in girls [22]. Current Sri Lankan study population shows more similar eruption times for permanent teeth when compared with the study conducted in Australia in 2003 [4]. Further, an Indian sample also shows a close finding which is compatible with our current study results; perhaps as a neighboring country in the Asian region [6].

Table 4. Comparison of mean eruption ages (years) of Sri Lankan girls with those of other nationalities in the respective year of study

\begin{tabular}{|c|c|c|c|c|c|c|c|c|}
\hline Jaw & Tooth & $\begin{array}{l}\text { Sri Lanka } \\
\text { (Present } \\
\text { study) }\end{array}$ & $\begin{array}{l}\text { Australia } \\
\text { (2003)[4] }\end{array}$ & $\begin{array}{l}\text { USA } \\
(1978)[22]\end{array}$ & $\begin{array}{l}\text { Finland } \\
(1999)[23]\end{array}$ & $\begin{array}{l}\text { Uganda } \\
(2003)[21]\end{array}$ & $\begin{array}{l}\text { India } \\
(2011)[6]\end{array}$ & $\begin{array}{l}\text { Nepal } \\
(2016)[24]\end{array}$ \\
\hline \multirow[t]{7}{*}{ Maxilla } & CI & 7.63 & 7.20 & 7.20 & 6.75 & 6.20 & 7.46 & 8.50 \\
\hline & LI & 8.91 & 8.20 & 8.20 & 7.64 & 7.20 & 8.54 & 9.50 \\
\hline & C & 11.12 & 11.20 & 11.00 & 10.81 & 9.30 & 11.20 & 11.50 \\
\hline & PM1 & 10.235 & 10.80 & 10.50 & 10.32 & 9.30 & 10.50 & 11.00 \\
\hline & PM2 & 11.071 & 11.70 & 12.20 & 10.81 & 10.10 & 11.21 & 12.00 \\
\hline & M1 & 6.49 & 6.60 & 6.40 & 6.13 & 5.30 & 5.40 & 7.00 \\
\hline & M2 & 12.38 & 12.30 & 12.10 & 11.90 & 10.70 & 12.30 & 12.50 \\
\hline \multirow[t]{7}{*}{ Mandible } & CI & 6.97 & 6.40 & 6.10 & 5.85 & 5.60 & 6.90 & 7.00 \\
\hline & LI & 7.95 & 7.50 & 7.30 & 6.82 & 6.80 & 7.90 & 8.50 \\
\hline & $\mathrm{C}$ & 10.27 & 10.10 & 9.90 & 9.74 & 9.70 & 10.50 & 11.00 \\
\hline & PM1 & 10.64 & 10.60 & 10.40 & 10.27 & 9.20 & 11.21 & 11.00 \\
\hline & P M2 & 11.27 & 11.70 & 11.10 & 11.32 & 10.20 & 11.50 & 11.50 \\
\hline & M1 & 6.23 & 6.40 & 6.30 & 6.10 & 5.20 & 5.18 & 7.00 \\
\hline & M2 & 11.87 & 11.80 & 11.80 & 11.59 & 10.30 & 11.90 & 12.50 \\
\hline
\end{tabular}


However, the different sampling and research methodology may explain the differences identified with the given table. Furthermore, some researchers have identified a genetic influence on early and late emergence of teeth as well $[16,23]$. Some researchers have also studied the effect of decayed and extracted primary teeth on eruption of their permanent successors [24]. Factors such as genetic influences and hormonal status of the study sample can be speculated to produce above diverging results [25].

\section{Conclusion}

In conclusion, the results of the present study provide reliable references for the emergence of permanent teeth in Sri Lankan children. Generally median emergence times were delayed compared with those reported in earlier. However, it may be important to conduct a further study with different ethnic groups of the country as the Sri Lanka is a multi ethnic country.

\section{Conflicts of Interests}

There are no conflicts of interest.

\section{Funding}

Self funding.

\section{References}

1. Krishan K, Kanchan T, Garg AK. Dental Evidence in Forensic Identification - An Overview, Methodology and present status. The Open Dentistry Journal 2015; 9: 250-6.

2. Nystrom M, Kleemoola Kujala E, Evalahit M, Peck L, Kataja M. Emergence of permanent teeth and dental age in a series of Finns. Acta Odontol Scand 2001; 59: 49-56.

3. Lerory R, Lesaffru E, Declerek D. The emergence of permanent teeth in Flemish Children. J Communit Dent. Oral Epidemiol 2003; 31: 30-9.

4. Diamanti J, Townsend GC. New standards for permanent tooth emergence in Australian children. Australi. Dental Journal 2003; 48(1): 39-42.

5. Khan N. Eruption time of permanent teeth in Pakistani Children. Iranian Journal of Public Health 2011; 40 (4): 63-73.

6. Lakshmappa A, Guledgud MV, Patil K. Eruption times and patterns of permanent teeth in school children of India. Indian Journal of Dental Research 2011; 22(6): 755-63.

7. Yamaguchi K, Holman DJ. Longitudinal analysis of permanent tooth emergence in Japanese children. Anthropological Science 2010; 18( 2): 141-9.

8. NanayakkaraCD,Chandresekara MS, Wikramanayake ER. Norms for the eruption of the permanent dentition in the Sinhalese of Kandy district. The Ceylon Journal of Medical Science1993; 36: 23-27.
9. Khan N. Eruption time of permanent teeth in Pakistani children. Iranian Journal of Public Health 2011: 40(4): 63-73.

10. Hagg U, Taranger J. Timing of tooth emergence. A prospective longitudinal study of Swedish urban children from birth to 18 years. Swed Dent J 1986; 10: 195-206.

11. Dahlberg AA, Menegaz - Bock RM. Emergence of the permanent teeth in Pima Indian children. J Dent Res. 1958; 37: 1123-40.

12. Kanagaratnam S, Schluter PJ. The age of permanent tooth emergence in children of different ethnic origin in the Auckland region: a cross-sectional study. New Zealand Dental Journal 2012; 108(2): 55-61.

13. Yamaguchi K, Holman DJ. Longitudinal analysis of permanent tooth emergence in Japanese children. Anthropological Science 2010; 118( 2): 141-9.

14. Kochhar R, Richardson A. Achronology and sequence of eruption of human permanent teeth in Northern Ireland. Int. J Paediatric Dent 1998; 8(4): 243-52.

15. Pahkala R, Pahkala A, Laine T. Eruption pattern of permanent teeth in a rural community in northeastern Finland. Acta Odontol Scand 1991; 49: 341-9.

16. Garcia- Godoy F, Diaz AN, del Valle JM, Arana EJ. Timing of permanent tooth emergence in a South Eastern Dominican School children population sample. J Community Dental Oral Epidemiol. 1982; 10: 43-6.

17. Diamanti J, Townsend GC. New standards for permanent tooth emergence in Australian children. Australi. Dental Journal 2003; 48:(1) 39-42.

18. National oral health survey Sri Lanka 2015 - 2016, Ministry of Health Nutrition and Indigenous Medicine. 2018; 33-8

19. Kutesa A, Nkamba EM, Muwazi L, Buwembo W, Rwenyony CM. Weight, height and eruption times of permanent teeth of children aged 4-15 years in Kampala, Uganda. BMC Oral Health 201: 13-15.

20. Holly SB, Garn S. Polymorphisms in eruption sequence of permanent teeth in American children. American Journal of Physical Anthropology 1987; 74: 289-303.

21. Eskeli R, Laine-Alava MT, Hausen H, Pahkala R. Standards for permanent tooth emergence in Finnish children. The Angle Orthodontist 1999; 69(6): 529-33.

22. Upadhyay S, Shrestha R, Shrestha D, Poudyal S. Permanent Teeth Emergence Time and Sequence in Children of Kavre District, Nepal. Kathmandu University Medical Journal 2016; 55(3): 269-73.

23. Kjaer I. Mechanism of Human Tooth Eruption: Review Article Including a New Theory for Future Studies on the Eruption Process. Scientifica 2014; 341905.

24. Haralabakis NB, Yiagtzis SC,Toutountzakis NM. Premature or delayed exfoliation. J Angle Ortho 1994; 64: 151-7.

25. Ritva E, Maija T, Laine-Alava, Hannu H, Ritta P. Standards for permanent tooth emergence in Finnish children. J Angle Ortho 1999; 69(6): 529-33. 